\title{
The Impact of Covid-19 Experiences and Associated Stress on Anxiety, Depression, and Functional Impairment in American Adults
}

\author{
Matthew W. Gallagher ${ }^{1,2}\left(\right.$ D $\cdot$ Michael J. Zvolensky ${ }^{1,3} \cdot$ Laura J. Long $^{1} \cdot$ Andrew H. Rogers $^{1} \cdot$ Lorra Garey $^{1}$
}

Published online: 29 August 2020

(c) Springer Science+Business Media, LLC, part of Springer Nature 2020

\begin{abstract}
Background The COVID-19 pandemic has had a profound impact on health and well-being worldwide and there is increasing recognition of the need to understand the psychological impact of COVID-19 experiences and stress in addition to the physical health consequences.

Methods The present study examined how experiences related to COVID-19 and associated stress impact, anxiety, depression, and functional impairment in a convenience sample of 565 American adults (57.9\% male) recruited through MTURK. Results COVID-19 experiences were consistently associated with higher odds of probable anxiety and depression diagnoses (ORs $\geq 3.0)$. COVID-19 associated stress also predicted large proportions of variance $\left(R^{2} \geq 30\right)$ in anxiety, depression, health anxiety, and functional impairment in latent variable analyses.

Conclusions These findings highlight that personal experiences related to the diagnosis of COVID-19, mortality in acquaintances, and COVID-19 associated stress is associated with a greatly elevated risk of emotional disorder symptomatology and that the COVID-19 pandemic may result in increased demand for mental health services.
\end{abstract}

Keywords COVD-19 $\cdot$ Coronavirus $\cdot$ Stress $\cdot$ Anxiety $\cdot$ Depression

The 2019 novel coronavirus (COVID-19) has had a devastating health and economic impact on the world, with upwards of 20.5 million people infected worldwide and over 750,000 associated deaths as of August 12th, 2020 (John Hopkins University 2020). Beyond the impact on physical health, the ongoing uncertainty related to the pandemic and the dramatic changes in behavior required by social distancing efforts may uniquely and profoundly impact mental health (Gruber et al. 2020; Pfefferbaum and North 2020; Wang et al. 2020). Prevalence of anxiety and depressive disorders may increase due to exacerbated and sustained stress related to COVID-19 given the role of stress in the etiology of these disorders. There is also preliminary evidence that these symptoms and disorders may be associated with more severe

Matthew W. Gallagher

mwgallagher@uh.edu

1 Department of Psychology, University of Houston, 4849 Calhoun Rd, Rm 373, Houston, TX, USA

2 Texas Institute for Measurement Evaluation and Statistics, Houston, TX, USA

3 Department of Behavioral Science, The University of Texas MD Anderson Cancer Center, Houston, TX, USA
COVID-19 progression (Yao et al. 2020). Further, given that COVID-19 is on track to be a leading cause of death in 2020, the psychological impact of grief is likely to be substantial (Wallace et al. 2020). Additionally, social distancing measures, while critical to curtail disease spread, have decreased critically important social supports to help manage these increases in psychological symptoms and increased loneliness (Armitage and Nellums 2020). It is therefore important to examine how personal experiences with the COVID-19 pandemic impact the development and maintenance of anxiety and depressive disorders.

Functional impairment is also likely to be impacted by COVID-19. While research examining the direct impact of COVID-19 on functional impairment is limited, past work among other medical illnesses suggests that increased disease severity is associated with greater functional impairment (Littlefield et al. 1990). Additionally, pertinent to the current investigation, it appears that the link between disease severity and functional impairment largely depends on mental health responses (i.e. anxiety and depression) to the illness (Kim et al. 2000). Therefore, it is plausible that psychological responses to COVID-19 may exacerbate the 
relationship between COVID-19 experience and functional impairment.

Although there is increasing recognition of the need to examine the mental health impact of the COVID-19 pandemic (Gruber et al. 2020; Reger et al. 2020), little empirical work has demonstrated how mental health may be impacted differentially by COVID-19 experience, including probable diagnosis, confirmed diagnosis, knowing someone with diagnosis, and knowing someone who died from COVID19. This lack of data is unfortunate given that extant work has suggested that being diagnosed with a serious medical illness, such as COVID-19, is associated with poorer mental health (Moos and Schaefer 1984; Turner and Baker 2010). Furthermore, given that a significant percentage of COVID19 patients require hospital-level care, COVID-19 is likely to cause significant familial and caretaker burden (Hickman and Douglas 2010). Additionally, grief associated with death of a loved one due to COVID-19 is likely to have a major impact on mental and physical health worldwide (Ott 2003). Preliminary work predicts that COVID-19 associated grief is likely to be elevated and associated with functional impairment (Eisma et al. 2020). Understanding how COVID-19 experiences differentially relate to mental health has direct implications for tailoring treatment and prevention efforts.

In addition to COVID-19 experiences, perceived stress related to COVID-19 also likely plays a major role in the increase of poorer mental health outcomes. Perceived stress reflects the degree to which one appraises their life as stressful by tapping into how unpredictable, uncontrollable, and overloaded one perceives their life (Cohen et al. 1983; Lee 2012). Perceived stress has been implicated as a risk factor for poorer mental and physical health outcomes, including anxiety, depression, and cardiovascular disease (Lee 2012; Redmond et al. 2013). Considering the current pandemic, which has been characterized by unpredictability, lack of control, and increased responsibilities to provide daily child care due to school closure, perceived stress specific to COVID-19 may be centrally important to study in the context of mental and physical health outcomes. Theoretically, while the experience of COVID-19 itself (being diagnosed or knowing someone who had it/died from it) is likely to cause significant stress, the state of chronic COVID-19-associated stress may further amplify these mental health states. This perspective is in line with the allostatic load model (McEwen 2005), indicating that under states of chronic stress, the body experiences additional "wear and tear" which is associated with greater symptom presentation and functional impairment.

The current study examined the influence of COVID19 experiences on five clinically relevant psychological variables: COVID-19 specific perceived stress, anxiety, depression, health anxiety, and functional impairment. We hypothesized that those who believed they had contracted
COVID-19, received a medical confirmation of COVID19, knew someone with COVID-19, or knew someone who died from COVID-19 would report poorer mental health outcomes. Additionally, we explored the associations between perceived stress specific to COVID-19 and anxiety, depression, health anxiety, and functional impairment. We hypothesized that greater COVID-19 perceived stress would result in poorer mental health across the studied mental health indices.

\section{Methods}

\section{Participants}

A total of 603 American adults were recruited using amazon mechanical turk (MTURK), an online data collection platform that has been shown to be an effective method of obtaining reliable and valid data (Thomas and Clifford 2017). The survey was advertised as a study on mental health and the Coronavirus pandemic, and data collection occurred from March 27, 2020 to May 5, 2020. Participants were eligible if they 18 years or older, located in the United States, had completed at least 100 human intelligence tasks (HITS), and had an approval rate of at least 95\%. Participants were excluded if they did not complete the full survey or failed to answer at least three out of four validity questions correctly (e.g. "Respond to this question by writing the word 'apple' in the blank"). The final sample consisted of 565 participants with an average age of $38.26(\mathrm{SD}=12.13$; range 8-73). Most were male (57.9\%), heterosexual (84.6\%), married (52.9\%), employed (76.8\%), and had a bachelor's degree or higher level of education (61.6\%). Participants mostly identified as Caucasian (70.1\%), with the remaining identifying as African American/Black (13.6\%), Hispanic (6.2\%), Asian/Pacific Islander (4.2\%), Native American (2.8\%), or multiracial/other (3.0\%). The present study had a targeted sample size of 500 based on an a-priori power analysis indicating that this sample size would provide power greater than 0.80 to detect small to medium associations $(r \mathrm{~s}$ $\geq 0.20$ ) at alpha of 0.01 .

\section{Materials}

\section{Coronavirus Experiences}

The survey included questions that were developed to understand participants' experiences during Coronavirus pandemic. Participants reported on four specific COVID-19 experiences: "Do you believe that you may have contracted the Coronavirus (i.e. COVID-19)?", "Have you received results confirming that you have a diagnosis of COVID-19 by a public health official?", "Do you know someone who 
has contracted the Coronavirus?" and "Has somebody you know died after contracting the Coronavirus?". Response options were "yes" or "no" for these questions. In addition, a modified version of the Perceived Stress Scale (Cohen et al. 1983) with items pertaining specifically to COVID19 was included. Responses to the ten items were recorded on a five-point Likert scale. The reliability of the scale was high (Cronbach's $\alpha=0.83$ ) and preliminary factor analyses supported the unidimensionality of this COVID-19 stress outcome.

\section{Mental Health Outcomes}

Participants also completed self-report measures of anxiety and depression. The survey included the Overall Anxiety Severity and Impairment Scale (OASIS; Norman et al. 2006) and Overall Depression Severity and Impairment Scale (ODSIS; Bentley et al. 2014). Each measure contains five questions rated on a five-point Likert scale. Past psychometric work using receiver operating characteristic curves have demonstrated that cutoffs of $\geq 8$ for both the OASIS and ODSIS provide good sensitivity and specificity for identifying clinically significant levels of anxiety and depression, respectively (Bentley et al. 2014; Campbell-Sills et al. 2009; Norman et al. 2011). Reliability was high for both the OASIS (Cronbach's $\alpha=0.91$ ) and ODSIS (Cronbach's $\alpha=0.94$ ). In addition, the health anxiety inventory-short form (HAI-SF; Salkovskis et al. 2002) was used to assess health-specific anxiety. This scale includes 18 sets of four statements that participants may endorsed, and responses are scored 0-4 so that higher scores indicate greater health anxiety. Reliability was high for the HAI-SF (Cronbach's $\alpha=0.93)$.

\section{Functional Impairment}

The Work and Social Adjustment Scale (WSAS; Mundt et al. 2002) was used to measure impairment in functioning. This self-report measure contains five questions assessing impairment in the following five life domains: work, home management, social leisure activities, private leisure activities, and family and relationships. Level of impairment was rated from 0 (not at all) to 8 (very severely) for each item. The reliability of the scale was high in the present study (Cronbach's $\alpha=0.97$ ).

\section{Data Analysis}

Analyses consisted of effect sizes calculations to examine differences in outcomes between individuals with or without the four COVID-19 experiences (cohen's d with 95\% $\mathrm{CI}$ ) and examining the likelihood (odds ratios with 95\% CI) of clinically significant levels of anxiety/depression based on OASIS/ODSIS cutoffs in individuals with or without the four COVID-19 experiences. Structural equation modeling (SEM) was then used to quantify the latent effects of COVID-19 associated perceived stress on the outcomes of anxiety, depression, health anxiety, and functional impairment. SEM analyses were conducted using Mplus 8.0 (Muthén and Muthén 1998-2016) and robust maximum likelihood estimation. The COVID-19 perceived stress and health anxiety latent variables were identified using three parcels that were created by randomly assigning items from the respective scales as indicators. The anxiety, depression, and functional impairment latent variables were identified using the five items from the respective scales as indicators. Model fit for the SEM analyses was evaluated using common model fit indices: root-mean-square error of approximation (RMSEA; Steiger 1990), the Tucker-Lewis index (TLI; Tucker and Lewis 1973), the comparative fit index (CFI; Bentler 1990), and the standardized root-mean-square residual (SRMR; Jöreskog and Sörbom 1996). Acceptable model fit was evaluated using standard model fit criteria: RMSEA and SRMR values below 0.08, and CFI and TLI values above 0.95 (Hu and Bentler 1998).

\section{Results}

Means, standard deviations, and correlations among the five continuous outcomes are presented in Table 1. All correlations among the variables were at least moderate to large in magnitude ( $r s>0.483)$ and statistically significant $(p<0.001)$. Rates of probable anxiety or depressive disorder were high $(38.41 \%$ and $31.33 \%$, respectively) based on OASIS/ODSIS cutoffs.

Comparisons of mean levels and effect sizes (cohen's d) for the five outcomes in relation to the four COVID-19 experiences examined are reported in Table 2. Participants

Table 1 Means, standard deviations, and correlations among outcomes

\begin{tabular}{llllll}
\hline Outcome & 1 & 2 & 3 & 4 & 5 \\
\hline 1. COVID-19 perceived stress & 1 & & & & \\
2. Anxiety (OASIS) & 0.612 & 1 & & & \\
3. Depression (ODSIS) & 0.560 & 0.796 & 1 & & \\
4. Health anxiety (HAI-sf) & 0.542 & 0.670 & 0.661 & 1 & \\
5. Functional impairment & 0.484 & 0.580 & 0.625 & 0.483 & 1 \\
$\quad$ (WSAS) & & & & & \\
M & 16.59 & 16.88 & 6.10 & 4.85 & 11.17 \\
SD & 7.53 & 10.43 & 4.96 & 5.09 & 13.02 \\
\hline
\end{tabular}

All correlations $p<.001$

OASIS Overall Anxiety Severity and Impairment Scale, ODSIS Overall Depression Severity and Impairment Scale, HAI-sf Health Anxiety Inventory Short Form, WSAS Work and Social Adjustment Scale 
Table 2 Mean level differences and effect size comparisons of outcomes in relation to four COVID-19 experiences

\begin{tabular}{|c|c|c|c|c|c|c|c|c|c|c|}
\hline \multirow[t]{2}{*}{ Experience } & \multirow[t]{2}{*}{ Outcome } & \multicolumn{3}{|l|}{ Yes } & \multicolumn{3}{|l|}{ No } & \multicolumn{3}{|c|}{ Yes vs no } \\
\hline & & $\mathrm{N}$ & M & SD & $\mathrm{N}$ & M & $\mathrm{SD}$ & d & LL & UL \\
\hline \multirow[t]{5}{*}{ Belief of COVID-19 diagnosis } & COVID-19 perceived stress & 121 & 21.11 & 4.79 & 444 & 15.36 & 7.68 & 0.80 & 0.60 & 1.01 \\
\hline & Anxiety (Oasis) & 121 & 9.96 & 4.30 & 444 & 5.05 & 4.59 & 1.08 & 0.87 & 1.29 \\
\hline & Depresion (Odsis) & 121 & 8.13 & 4.40 & 444 & 3.95 & 4.90 & 0.87 & 0.66 & 1.08 \\
\hline & Health anxiety (Hai-sf) & 121 & 24.61 & 9.28 & 444 & 14.77 & 9.71 & 1.02 & 0.47 & 1.57 \\
\hline & Functional impairment (Wsas) & 121 & 24.37 & 10.83 & 444 & 7.57 & 11.11 & 1.52 & 1.30 & 1.74 \\
\hline \multirow[t]{5}{*}{ Confirmed COVID-19 diagnosis } & COVID-19 perceived stress & 89 & 20.98 & 3.56 & 476 & 15.77 & 7.80 & 0.71 & 0.48 & 0.94 \\
\hline & Anxiety (Oasis) & 89 & 11.07 & 3.88 & 476 & 5.17 & 4.57 & 1.32 & 1.08 & 1.56 \\
\hline & Depresion (Odsis) & 89 & 9.43 & 4.28 & 476 & 3.99 & 4.77 & 1.16 & 0.92 & 1.39 \\
\hline & Health anxiety (Hai-sf) & 89 & 25.78 & 9.62 & 476 & 15.22 & 9.72 & 1.09 & 0.85 & 1.32 \\
\hline & Functional impairment (Wsas) & 89 & 28.03 & 7.52 & 476 & 8.02 & 11.29 & 1.85 & 1.60 & 2.10 \\
\hline \multirow[t]{5}{*}{ Know Someone diagnosed with COVID-19 } & COVID-19 perceived stress & 163 & 19.09 & 6.67 & 402 & 15.57 & 7.64 & 0.48 & 0.29 & 0.66 \\
\hline & Anxiety (Oasis) & 163 & 8.36 & 4.93 & 402 & 5.18 & 4.67 & 0.67 & 0.48 & 0.86 \\
\hline & Depresion (Odsis) & 163 & 6.90 & 4.99 & 402 & 4.01 & 4.90 & 0.59 & 0.40 & 0.77 \\
\hline & Health anxiety (Hai-sf) & 163 & 20.83 & 10.61 & 402 & 15.28 & 9.93 & 0.55 & 0.36 & 0.73 \\
\hline & Functional impairment (Wsas) & 163 & 17.62 & 13.66 & 402 & 8.55 & 11.80 & 0.73 & 0.55 & 0.92 \\
\hline \multirow[t]{5}{*}{ Know someone deceased due to COVID-19 } & COVID-19 perceived stress & 92 & 20.82 & 4.57 & 473 & 15.77 & 7.72 & 0.69 & 0.46 & 0.92 \\
\hline & Anxiety (Oasis) & 92 & 10.13 & 4.49 & 473 & 5.32 & 4.66 & 1.04 & 0.81 & 1.27 \\
\hline & Depresion (Odsis) & 92 & 8.54 & 4.50 & 473 & 4.13 & 4.89 & 0.91 & 0.68 & 1.14 \\
\hline & Health anxiety (Hai-sf) & 92 & 24.01 & 10.24 & 473 & 15.49 & 9.89 & 0.86 & 0.63 & 1.08 \\
\hline & Functional impairment (Wsas) & 92 & 24.83 & 11.45 & 473 & 8.51 & 11.57 & 1.41 & 1.17 & 1.65 \\
\hline
\end{tabular}

All correlations $p<.001$

OASIS Overall Anxiety Severity and Impairment Scale, ODSIS Overall Depression Severity and Impairment Scale, HAI-sf Health Anxiety Inventory Short Form, WSAS Work and Social Adjustment Scale

who endorsed experiencing each COVID-19 experience reported statistically significantly greater levels of all five outcomes examined. The magnitude of the differences was generally moderate to large in effect size magnitude and greatest for reported confirmation of a COVID-19 diagnosis and reported knowledge of an acquaintance who died due to COVID-19. Of the five outcomes examined, the largest difference between participants with or without the four experiences was consistently in levels of functional impairment. These results indicate that self-reported personal experiences related to the COVID-19 pandemic are associated with clinically significant higher levels of stress, anxiety, depression, and functional impairment. Participants who believed they may have contracted COVID-19 reported means for OASIS (9.96; SD = 4.30) and ODSIS (8.13; SD = 4.40) comparable to levels in clinical trials for anxiety disorders (Barlow et al. 2017).

\section{Likelihood of Anxiety/Depression Diagnoses in Relation to Four COVID-19 Experiences}

The comparative frequencies of meeting cutoff criteria for a probable anxiety or depressive disorder as a function of the four COVID-19 experiences and the odds ratio effect size (with 95\% CI) for these comparisons are presented in Table 3. Each of the four experiences examined was associated with increased likelihood of a probable anxiety disorder diagnosis and a probable depressive disorder diagnosis (all effects $p<0.001$ ). Participants who reported having received a diagnosis of COVID-19 confirmed by a public health official had the highest odds of meeting criteria for a probable anxiety/depression diagnosis.

\section{Latent Associations Between COVID-19 Stress and Mental Health Outcomes}

The impact of COVID-19 associated perceived stress on the four outcomes of anxiety, depression, health anxiety, and functional impairment were then examined using SEM. A CFA was specified first in which all five latent variables 
Table 3 Frequencies and odds ratios of probable anxiety/depression diagnosis by self-reported COVID-19 experiences

\begin{tabular}{|c|c|c|c|c|c|c|}
\hline \multirow{2}{*}{$\begin{array}{l}\text { COVID-19 experi- } \\
\text { ence }\end{array}$} & \multicolumn{2}{|l|}{ Yes } & \multicolumn{2}{|l|}{ No } & \multirow[t]{2}{*}{ Chi-square } & \multirow[t]{2}{*}{ Odds ratio $95 \% \mathrm{C}$} \\
\hline & Above cutoff no. (\%) & Below cutoff no. (\%) & Above cutoff no. (\%) & Below cutoff no. (\%) & & \\
\hline \multicolumn{7}{|l|}{ Anxiety (OASIS) } \\
\hline $\begin{array}{l}\text { Do you believe that } \\
\text { you may have } \\
\text { contracted the } \\
\text { coronavirus (i.e. } \\
\text { COVID-19)? }\end{array}$ & $88(72.73 \%)$ & $33(27.27 \%)$ & $129(29.05 \%)$ & $315(70.95 \%)$ & $76.67 *$ & $6.51(4.15: 10.21)$ \\
\hline $\begin{array}{l}\text { Have you received } \\
\text { results confirm- } \\
\text { ing that you have } \\
\text { a diagnosis of } \\
\text { COVID-19 by } \\
\text { a public health } \\
\text { official? }\end{array}$ & $75(84.27 \%)$ & $14(15.73 \%)$ & $142(29.83 \%)$ & $334(70.17 \%)$ & $93.93 *$ & $12.6(6.89: 23.04)$ \\
\hline $\begin{array}{l}\text { Do you know } \\
\text { someone who has } \\
\text { contracted the } \\
\text { Coronavirus? }\end{array}$ & $99(60.74 \%)$ & $64(39.26 \%)$ & $118(29.35 \%)$ & $284(70.65 \%)$ & $48.29 *$ & $3.72(2.54: 5.45)$ \\
\hline $\begin{array}{l}\text { Has somebody you } \\
\text { know died after } \\
\text { contracting the } \\
\text { Coronavirus? }\end{array}$ & $68(73.91 \%)$ & $24(26.09 \%)$ & $149(31.5 \%)$ & $324(68.5 \%)$ & $58.57 *$ & $6.16(3.72: 10.2)$ \\
\hline \multicolumn{7}{|l|}{ Depression (ODSIS) } \\
\hline $\begin{array}{l}\text { Do you believe that } \\
\text { you may have } \\
\text { contracted the } \\
\text { coronavirus (i.e. } \\
\text { COVID-19)? }\end{array}$ & $73(60.33 \%)$ & $48(39.67 \%)$ & $104(23.42 \%)$ & $340(76.58 \%)$ & $60.21 *$ & $4.97(3.25: 7.61)$ \\
\hline $\begin{array}{l}\text { Have you received } \\
\text { results confirm- } \\
\text { ing that you have } \\
\text { a diagnosis of } \\
\text { COVID-19 by } \\
\text { a public health } \\
\text { official? }\end{array}$ & $63(70.79 \%)$ & $26(29.21 \%)$ & $114(23.95 \%)$ & $362(76.05 \%)$ & $76.46^{*}$ & $7.69(4.65: 12.72)$ \\
\hline $\begin{array}{l}\text { Do you know } \\
\text { someone who has } \\
\text { contracted the } \\
\text { Coronavirus? }\end{array}$ & $80(49.08 \%)$ & $83(50.92 \%)$ & $97(24.13 \%)$ & $305(75.87 \%)$ & $33.56^{*}$ & $3.03(2.07: 4.44)$ \\
\hline $\begin{array}{l}\text { Has somebody you } \\
\text { know died after } \\
\text { contracting the } \\
\text { Coronavirus? }\end{array}$ & $59(64.13 \%)$ & $33(35.87 \%)$ & $118(24.95 \%)$ & $355(75.05 \%)$ & $54.97 *$ & $5.38(3.35: 8.64)$ \\
\hline
\end{tabular}

OASIS Overall Anxiety Severity and Impairment Scale, ODSIS Overall Depression Severity and Impairment Scale, CI confidence intervals $* p<0.001$

freely associated with one another to evaluate measurement and latent associations. The model fit for the CFA was good $\left[\chi^{2}(d f=179)=494.99, p>.05, \mathrm{RMSEA}=0.06, \mathrm{TLI}=.95\right.$, $\mathrm{CFI}=.96 ; \mathrm{SRMR}=.04]$. A structural model was then specified in which the latent variable of perceived stress predicted the four outcomes (Fig. 1). The model fit for this structural model was identical to that of the CFA. As expected, latent effects of COVID-19 stress were large and statistically significant for all four outcomes. The unstandardized and completely standardized effects of perceived stress and the variance explained $\left(R^{2}\right.$ with $95 \%$ CI) are presented in Table 4. COVID-19 perceived stress predicted at least $30 \%$ of the variance in all four outcomes but had the strongest association with anxiety $\left(R^{2}\right.$ of .467). 


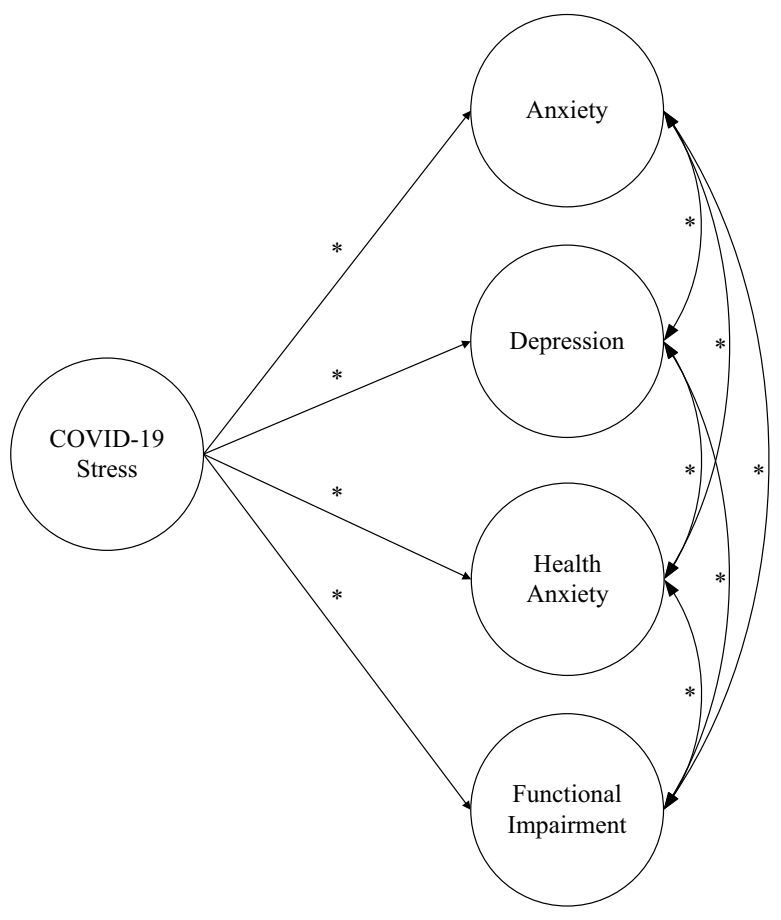

Fig. 1 Structural equation model examining the effects of COVID-19 perceived stress on anxiety, depression, health anxiety, and functional impairment

\section{Discussion}

The present study evaluated the differential impact of four critical COVID-19 experienced on mental health outcomes as well as COVID-19 related perceived stress on mental health. Study results indicated that those who endorsed relevant coronavirus experiences demonstrated higher levels of stress, poorer mental health outcomes, and greater levels of functional impairment in particular, with the worst outcomes associated with a confirmed COVID-19 diagnosis and death of a loved one. Notably, nearly one-third of the sample met the clinical cutoff for probable anxiety and depressive disorders, and the likelihood of meeting criteria for probable anxiety and depression was significantly greater for those who endorsed believing or having been diagnosed with COVID-19 as well as knowing someone who was diagnosed or died from COVID-19. In addition, greater coronavirus-related perceived stress was a strong predictor of higher functional impairment as well as health anxiety, and predicted symptoms of depressive and anxiety disorders. Our findings provide further evidence of the significant impact that the COVID-19 pandemic is having on mental health and the need for clinical psychological science to effectively identify and provide services for individuals and communities struggling with COVID-19 associated mental health issues (Gruber et al. 2020).

The adverse impact of coronavirus experiences and stress on mental health and functioning is consistent with the broader literature on the psychological effects of medical illness and contemporary work focused on the COVID19 pandemic. Medical illness more broadly is associated with poorer psychological outcomes, including symptoms of anxiety, depression, and stress, as well as greater functional impairment (Turner and Baker 2010). Research regarding the large scale spread of infectious diseases such as severe acute respiratory syndrome (SARS), the $2009 \mathrm{H} 1 \mathrm{~N} 1$ influenza, the Ebola virus, and HIV/AIDS also suggests that these illnesses can negatively impact mental health and psychosocial functioning (Busby et al. 2012; Coughlin 2012; De Roo et al. 1998; Mak et al. 2009). Similarly, current research has observed elevated symptoms of depression, anxiety, and stress among those who have contracted COVID-19, which may contribute to more severe disease progression (Yao et al. 2020).

Although it may be unsurprising that COVID-19 experiences and associated stress related to worse anxiety, depression, and functional impairment, the large effects are clinically noteworthy. American public health initiatives have understandably focused on promoting safety through social distancing and minimizing transmission, but there may soon be an epidemic of related anxiety and distress. These critical efforts to contain the virus may unfortunately impede typical methods of coping by restricting access to social support and public leisure activities. Furthermore, with provisional death counts for COVID-19 exceeding 100,000 in the U.S. (Johns Hopkins University 2020), the pandemic may also result in
Table 4 Latent effects of COVID-19 associated stress on outcomes in SEM analysis

\begin{tabular}{lllllll}
\hline Outcome & $\mathrm{b}$ & $s e$ & $p$ & $B$ & $95 \%$ CI $B$ & $R^{2}$ \\
\hline Anxiety (OASIS) & 0.190 & 0.011 & $<0.001$ & 0.683 & $0.627: 0.739$ & 0.467 \\
Depression (ODSIS) & 0.202 & 0.012 & $<0.001$ & 0.631 & $0.576: 0.687$ & 0.398 \\
Health anxiety (HAI-SF) & 0.452 & 0.033 & $<0.001$ & 0.550 & $0.490: 0.610$ & 0.302 \\
Functional impairment (WSAS) & 0.634 & 0.041 & $<0.001$ & 0.601 & $0.546: 0.655$ & 0.361 \\
\hline
\end{tabular}

$\mathrm{b}$ represents unstandardized beta coefficient and $B$ represents completely standardized beta coefficient OASIS Overall Anxiety Severity and Impairment Scale, ODSIS Overall Depression Severity and Impairment Scale, HAI-sf Health Anxiety Inventory Short Form, WSAS Work and Social Adjustment Scale 
a rise in complicated grief due to disruption in the normal grieving process.

Though there is a dearth of research studying complicated grief in the wake of a pandemic, symptoms appear more common in the aftermath of other types of disasters or traumatic losses, and in some cases may persist for years afterwards (Kristensen et al. 2012; Sveen et al. 2018). The death of a loved one under traumatic circumstances may cause more duress because these types of losses are typically sudden and unexpected, and the grieving process is often more difficult. Deaths that occur in ICU may also be particularly distressing for loved ones who are unable to say their goodbyes, and these losses confer a greater risk of developing complicated grief as well as mental illness (Kentish-Barnes et al. 2015). The fact that deaths resulting from COVID-19 are commonly occurring in isolation raises concerns regarding the potential impact of complicated grief. Social distancing and isolation measures may preclude communal mourning and closure through funeral ceremonies, while also restricting access to social support in the aftermath of the loss.

Despite the increases in mental health symptoms associated with the COVID-19 outbreak, social distancing measures are limiting the amount of face-to-face contact, particularly with mental health providers. This limitation is critical to overcome, as theoretical studies suggest that the suicide rate is likely to rise during and in the aftermath of COVID19 (Klomek 2020). Interruptions to care may also disproportionately affect minority and low socioeconomic status groups who already have limited access to care. Considering these challenges, ongoing efforts of the field to adapt to telehealth are increasingly critical for reducing the burden of mental illness (Kazin and Blase 2011). Many providers may have been forced to adjust due to necessity, but a more concentrated effort must be made to reach populations that are traditionally underserved in receiving mental health services that are also being disproportionally impacted by pandemic.

The present study used a large sample of Americans to examine mental health and functioning during the COVID19 pandemic. However, this sample cannot be considered representative of the US population and study conclusions are limited by the online self-report method of assessment. In addition, the cross-sectional design cannot be used to establish causal relationships or determine the effects of the pandemic as they evolve overtime. Further, the sample was collected online, and while attention questions were included to minimize random responding, it is possible that participants were completing the survey while distracted, decreasing the reliability of the results. It would be important to replicate the results of the current study. Additionally, all measures in the current study were collected via selfreport, indicating that the observed results may be due to shared method variance. Future studies would benefit from including multi-method assessments to improve the generalizability of the findings. The use of recently developed measures that assess the facets of COVID-19 associated stress in greater detail (i.e., Taylor et al. 2020a) will also help to improve our understanding of the psychological impact of COVID-19 (Taylor et al. 2020b).

\section{Conclusions}

The present research provides initial evidence that the impact of COVID-19 on mental health outcomes may be worsened depending on one's experiences with the virus as well as the perceived stress related to COVID-19. Moreover, the relevant COVID-19 experiences are related to an increased likelihood of clinically significant anxiety and depression. As the pandemic continues to evolve and progress, there is an urgent need to continue to monitor the potential impact of COVID-19 specific outcomes on the onset and progression of poor mental health.

\section{Compliance with Ethical Standards}

Conflict of Interest Matthew W. Gallagher, Michael J. Zvolensky, Laura J. Long, Andrew H. Rogers, and Lorra Garey declare that they have no conflict of interest.

Ethical Approval Ethics approval was obtained from the IRB of the University of Houston.

Animal Rights No animal studies were carried out by the authors for this article.

Informed Consent Informed consent was obtained from all individual participants included in the study.

\section{References}

Armitage, R., \& Nellums, B. (2020). COVID-19 and the consequences of isolating the elderly. The Lancet Public Health, 5(5), e256. https://doi.org/10.1016/S2468-2667(20)30061-X.

Barlow, D. H., Farchione, T. J., Bullis, J. R., Gallagher, M. W., Latin, H., Sauer-Zavala, S., et al. (2017). The Unified Protocol for Transdiagnostic Treatment of Emotional Disorders compared with diagnosis-specific protocols for anxiety disorders: A randomized clinical trial. JAMA: Psychiatry, 74, 875-884. https://doi.org/10.1001/ jamapsychiatry.2017.2164.

Bentler, P. M. (1990). Comparative fit indexes in structural equation models. Psychological Bulletin, 28, 97-104. https://doi. org/10.1037/0033-2909.107.2.238.

Bentley, K. H., Gallagher, M. W., Carl, J. R., \& Barlow, D. H. (2014). Development and validation of the overall depression severity and impairment scale. Psychological Assessment, 26(3), 815-830. https://doi.org/10.1037/a0036216. 
Busby, K. K., Lytle, S., \& Sajatovic, M. (2012). Mental health comorbidity and HIV/AIDS. Mental Health Practitioner's Guide to HIV/ AIDS. https://doi.org/10.1007/978-1-4614-5283-6-2.

Campbell-Sills, L., Norman, S. B., Craske, M. G., Sullivan, G., Lang, A. J., Chavira, D. A., et al. (2009). Validation of a brief measure of anxiety-related severity and impairment: the Overall Anxiety Severity and Impairment Scale (OASIS). Journal of Affective Disorders, 112(1-3), 92-101.

Cohen, S., Kamarck, T., \& Mermelstein, R. (1983). A global measure of perceived stress. Journal of Health and Social Behavior, 24(4), 385-396. https://doi.org/10.2307/2136404.

Coughlin, S. S. (2012). Anxiety and depression: Linkages with viral diseases. Public Health Reviews. https://doi.org/10.1007/bf033 91675.

De Roo, A., Ado, B., Rose, B., Guimard, Y., Fonck, K., \& Colebunders, R. (1998). Survey among survivors of the 1995 ebola epidemic in Kikwit, Democratic Republic of Congo: Their feelings and experiences. Tropical Medicine and International Health, 3(11), 883-885. https://doi.org/10.1046/j.1365-3156.1998.00322.x.

Eisma, M. C., Boelen, P. A., \& Lenferink, L. I. (2020). Prolonged grief disorder following the coronavirus (COVID-19) pandemic. Psychiatry Research, 288, 113031. https://doi.org/10.1016/j.psych res.2020.113031.

Gruber, J., Prinstein, M. J., Clark, L. A., Rottenberg, J., Abramowitz, J. S., Albano, A. M., et al. (2020). Mental health and clinical psychological science in the time of COVID-19: Challenges, opportunities, and a call to action. American Psychologist. https://doi.org/10.1037/ amp0000707.

Hickman, R. L., Jr., \& Douglas, S. L. (2010). Impact of chronic critical illness on the psychological outcomes of family members. $A A C N$ Advanced Critical Care, 21(1), 80-91. https://doi.org/10.1097/ NCI.0b013e3181c930a3.

Hu, L., \& Bentler, P. M. (1998). Cutoff criteria for fit indexes in covariance structure modeling: Sensitivity to underparameterized model misspecification. Psychological Methods, 3, 424-453. https://doi. org/10.1080/10705519909540118.

Johns Hopkins University. (2020). COVID-19 dashboard by the Center for Systems Science and Engineering (CSSE) at Johns Hopkins University (JHU). Johns Hopkins University \& Medicine Coronavirus Resource Center. Retrieved from https://coronavirus.jhu.edu/map. html.

Jöreskog, K. G., \& Sörbom, D. (1996). LISREL 8: User's reference guide. Chicago: Scientific Software International.

Kazdin, A. E., \& Blase, S. L. (2011). Rebooting psychotherapy research and practice to reduce the burden of mental illness. Perspectives on Psychological Science, 6(1), 21-37. https://doi.org/10.1177/17456 91610393527.

Kentish-Barnes, N., Chaize, M., Seegers, V., Legriel, S., Cariou, A., Jaber, S., et al. (2015). Complicated grief after death of a relative in the intensive care unit. European Respiratory Journal, 45(5), 1341-1352. https://doi.org/10.1183/09031936.00160014.

Kim, H. F. S., Kunik, M. E., Molinari, V. A., Hillman, S. L., Lalani, S., Orengo, C. A., et al. (2000). Functional impairment in COPD patients: The impact of anxiety and depression. Psychosomatics, 41(6), 465-471. https://doi.org/10.1176/appi.psy.41.6.465.

Klomek, A. B. (2020). Suicide prevention during the COVID-19 outbreak. The Lancet Psychiatry, 7(5), 390. https://doi.org/10.1016/ S2215-0366(20)30142-5.

Kristensen, P., Weisæth, L., \& Heir, T. (2012). Bereavement and mental health after sudden and violent losses: A review. Psychiatry, 75, 76-97. https://doi.org/10.1521/psyc.2012.75.1.76.

Lee, E.-H. (2012). Review of the psychometric evidence of the perceived stress scale. Asian Nursing Research, 6(4), 121-127. https://doi. org/10.1016/j.anr.2012.08.004.

Littlefield, C. H., Rodin, G. M., Murray, M. A., \& Craven, J. L. (1990). Influence of functional impairment and social support on depressive symptoms in persons with diabetes. Health Psychology, 9(6), 737. https://doi.org/10.1037//0278-6133.9.6.737.

Mak, I. W. C., Chu, C. M., Pan, P. C., Yiu, M. G. C., \& Chan, V. L. (2009). Long-term psychiatric morbidities among SARS survivors. General Hospital Psychiatry, 31(4), 318-326. https://doi. org/10.1016/j.genhosppsych.2009.03.001.

McEwen, B. S. (2005). Stressed or stressed out: what is the difference? Journal of Psychiatry and Neuroscience, 30(5), 315.

Moos, R. H., \& Schaefer, J. A. (1984). The crisis of physical illness. In R. H. Moos (Ed.), Coping with physica illness (pp. 3-25). Boston: Springer.

Mundt, J. C., Marks, I. M., Shear, M. K., \& Greist, J. H. (2002). The work and social adjustment scale: A simple measure of impairment in functioning. The British Journal of Psychiatry, 180, 461-464. https ://doi.org/10.1192/bjp.180.5.461.

Muthén, L. K., \& Muthén, B. O. (1998-2016). Mplus 8.0. Los Angeles, CA: Author

Norman, S. B., Campbell-Sills, L., Hitchcock, C. A., Sullivan, S., Rochlin, A., Wilkins, K. C., et al. (2011). Psychometrics of a brief measure of anxiety to detect severity and impairment: the Overall Anxiety Severity and Impairment Scale (OASIS). Journal of psychiatric research, 45(2), 262-268.

Norman, S. B., Hami Cissell, S., Means-Christensen, A. J., \& Stein, M. B. (2006). Development and validation of an overall anxiety severity and impairment scale (OASIS). Depression and anxiety, 23(4), 245-249. https://doi.org/10.1002/da.20182.

Ott, C. H. (2003). The impact of complicated grief on mental and physical health at various points in the bereavement process. Death Studies, 27(3), 249-272. https://doi.org/10.1080/07481180302887.

Pfefferbaum, B., \& North, C. S. (2020). Mental health and the Covid19 pandemic. New England Journal of Medicine. https://doi. org/10.1056/NEJMp2008017.

Redmond, N., Richman, J., Gamboa, C. M., Albert, M. A., Sims, M., Durant, R. W., et al. (2013). Perceived Stress Is Associated With Incident Coronary Heart Disease and All-Cause Mortality in Lowbut Not High-Income Participants in the Reasons for Geographic And Racial Differences in Stroke Study. Journal of the American Heart Association, 2(6), e000447. https://doi.org/10.1161/ jaha.113.000447.

Reger, M. A., Stanley, I. H., \& Joiner, T. E. (2020). Suicide mortality and coronavirus disease 2019-A perfect storm? JAMA Psychiatry. https ://doi.org/10.1001/jamapsychiatry.2020.1060.

Salkovskis, P. M., Rimes, K. A., Warwick, H. M. C., \& Clark, D. M. (2002). The Health Anxiety Inventory: Development and validation of scales for the measurement of health anxiety and hypochondriasis. Psychological Medicine, 32(5), 843-853. https://doi.org/10.1017/ S0033291702005822.

Steiger, J. H. (1990). Structural model evaluation and modification: An interval estimation approach. Multivariate Behavioral Research, 25, 173-180. https://doi.org/10.1207/s15327906mbr2502_4.

Sveen, J., Bergh Johannesson, K., Cernvall, M., \& Arnberg, F. K. (2018). Trajectories of prolonged grief one to six years after a natural disaster. PLoS ONE, 13(12), e0209757. https://doi.org/10.1371/journ al.pone.0209757.

Taylor, S., Landry, C., Paluszek, M., Fergus, T. A., McKay, D., \& Asmundson, G. J. (2020a). Development and initial validation of the COVID stress scales. Journal of Anxiety Disorders, 72, 102232. https://doi.org/10.1016/j.janxdis.2020.102232.

Taylor, S., Landry, C. A., Paluszek, M. M., Fergus, T. A., McKay, D., \& Asmundson, G. J. (2020b). COVID stress syndrome: Concept, structure, and correlates. Depression and Anxiety, 37(8), 706-714.

Thomas, K. A., \& Clifford, S. (2017). Validity and mechanical turk: An assessment of exclusion methods and interactive experiments. Computers in Human Behavior, 77, 184-197. https://doi.org/10.1016/j. chb.2017.08.038. 
Tucker, L. R., \& Lewis, C. (1973). A reliability coefficient for maximum likelihood factor analysis. Psychometrika, 38, 10. https://doi. org/10.1007/BF02291170.

Turner, A., \& Baker, A. L. (2010). The psychological impact of serious illness. In D. B. Cooper (Ed.), Introduction to mental healthsubstance use (pp. 94-107). Radcliffe.

Wallace, C. L., Wladkowski, S. P., Gibson, A., \& White, P. (2020). Grief during the COVID-19 pandemic: Considerations for palliative care providers. Journal of Pain and Symptom Management. https://doi. org/10.1016/j.jpainsymman.2020.04.012.

Wang, C., Pan, R., Wan, X., Tan, Y., Xu, L., Ho, C. S., et al. (2020). Immediate psychological responses and associated factors during the initial stage of the 2019 coronavirus disease (COVID-19) epidemic among the general population in China. International Journal of Environmental Research and Public Health, 17(5), 1729. https:// doi.org/10.3390/ijerph1705172.

Yao, H., Chen, J. H., \& Xu, Y. F. (2020). Patients with mental health disorders in the COVID-19 epidemic. The Lancet Psychiatry, 7(4), e21. https://doi.org/10.1016/S2215-0366(20)30090-0.

Publisher's Note Springer Nature remains neutral with regard to jurisdictional claims in published maps and institutional affiliations. 